\section{Teoría urbana crítica y políticas de escala}

\section{Neil Brenner}

Alvaro Sevilla Buitrago (ed.). Icaria. Espacios Críticos. (2017). 292 págs.

DOI: http://dx.doi.org/10.19137/huellas-2018-2207
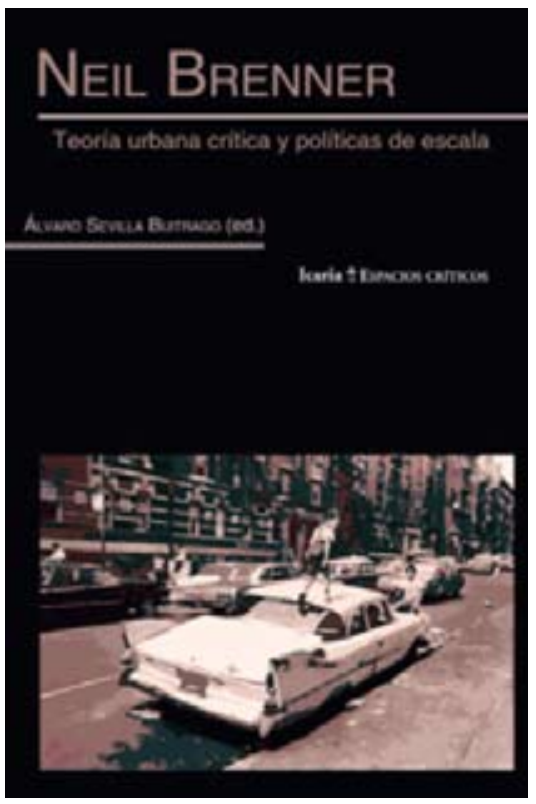

La presentación de este volumen integra una nutrida e indispensable colección de la editorial Icaria, radicada en la ciudad de Barcelona, que nuclea algunos de los principales autores de la geografía radical y la geografia crítica respectivamente contemporáneas. Muchas de estas obras provienen de geógrafos urbanos que comparten sus preocupaciones políticas y sociales desde la cuestión espacial hacia el ámbito teórico y empírico de los problemas de la urbanización capitalista. La colección cuenta además con otros cientistas sociales no geógrafos que se aproximaron en algún momento de su vida académica al campo de estudios de la geografía y adoptaron algunos soportes teóricos característicos de la imaginación espacial de la disciplina como arena para la formulación de renovados interrogantes teóricos y metodológicos.

Neil Brenner. Teoría urbana crítica y políticas de escala, editado por el arquitecto y urbanista Álvaro Sevilla Buitrago, es una antología de textos escritos mayoritariamente por Neil Brenner entre los años 1999 a 2015 que fueron traducidos al español para esta edición. La obra está estructurada en cinco secciones y una introducción previa de características biográficas que narra una parte importante de las experiencias académicas de nuestro autor en diferentes espacios; ello nos permite conocer su periplo intelectual desde los inicios de su formación como politólogo en la Universidad de Yale hacia el desarrollo de una creciente sensibilidad espacial crítica y un presente caracterizado por la dirección de numerosos y originales programas de investigación urbana con sede en el Urban Theory Lab -UTL- (Laboratorio de Teoría Urbana) de la Universidad de Harvard. Senderos, proyectos e instituciones (comolostransitados en Los Angeles, Chicago, Nueva York, Harvard y Berlín) parecen haber nutrido su formación en cada uno de los lugares mencionados. En el vínculo existente entre lugares e instituciones, Brenner, se introdujo y/o logró profundizar sus conocimientos acerca de la obra de Hegel, Nietzche, Heidegger, Marx, Weber, Gramsci y Foucault, amén de sus "estaciones intelectuales" en la Escuela de Frankfurt y una formación económica significativamente influida por diferentes versiones del regulacionismo económico francés y anglosajón.

Las dos primeras secciones que siguen a la introducción son de autoría del editor, Alvaro Sevilla Buitrago, quien ordena y resume algunos de los principales códigos 
de interpretación que contribuyen a la comprensión de diferentes momentos teóricos y conceptuales por venir en este volumen. Así, sobresale un primer capítulo a su cargo, estructurado en torno a "la forja de una teoría espacial del Estado". En su desarrollo destaca las críticas de Brenner a las interpretaciones reduccionistas de la globalización neoliberal así como la propensión de este de incorporar a las explicaciones estructurales del fenómeno, cuestiones tales como las economías políticas de escala, las estrategias y proyectos espaciales estatales del ahora "desaventajado" keynesianismo y "exitoso" neoliberalismo, y las políticas urbanas de localización y competitividad interurbana. El interés teórico gravita en los cambios organizacionales del espacio capitalista y en la influencia de la regulación estatal sobre los territorios de las metrópolis; la cuestión es puesta en evidencia al delimitar el status de los estados nacionales contemporáneos, que a su juicio, lejos de desaparecer son forzados a reorganizarse desde diversos desplazamientos/movimientos de escala hacia una reestructuración socioeconómica y territorial que es inseparable del fortalecimiento de formas de gobernanza de escala subnacional.

Los cambios de escala y las afectaciones espaciales propugnadas por la neoliberalizacion (esta la expresión / conjugación preferida por Brenner) estatal contemporánea estructuran el resto de los capítulos de la sección al convertirse en una parte significativa del "explicans" (aquello que proporciona la explicación o parte importante de ella) de la naturaleza del Estado capitalista actual. Dicho de otro modo, y tómese esto como una idea fuerza presente endistintos artículos de este volumen,la fase actual de reestructuración global capitalista reconfiguró desde el Estado la organización escalar de los procesos de territorialización del tipo fordista, relativizando/ desplazando, la primacía de la escala nacional y reforzado el rol y la relevancia de la escala subnacional y supranacional. Para Brenner, la escala de tipo subnacional cumple el rol de cadena de transmisión de programas elaborados a nivel estatal-nacional, mientras que las instituciones supranacionales operan como garantes de la estabilidad del mosaico global de los estados-nación. En suma, el espacio y la espacialidad -en sus diversas significaciones e incidencias concretas- son concebidas por un número importante de autores regulacionistas como un factor regulatorio socio-histórico y socio-económico claves; tal como por ejemplo aquí lo enuncian Alain Lipietz, Bob Jessop, a su modo David Harvey mediante el concepto de "arreglo espacial / spatialfix" y el propio Brenner. Por su parte, el capítulo también es recomendable por el esfuerzo pedagógico del editor al lograr reunir en un cuadro a doble página una parte significativa de la teoría urbana de los últimos cuarenta años; allí pone en paralelo hechos históricos, planes y programas urbanos paradigmáticos, debates teóricos, temas de estudio, obras, autores, influencias y paradigmas teóricos vinculados a Brenner y su perspectiva, junto a la mención a "lugares" en los que se estructuraron estos discursos y prácticas académicas del urbanismo crítico.

La segunda sección, conformada por un solo y extenso capítulo, es una "conversación" mantenida entre el editor y Brenner que lleva como título:Estado, escala, urbanización (...); de allísurgen numerosos postulados e interrogantes en clave teórica y metodológica,que envían a Harvey y fundamentalmente a Henri Lefebvre, entre otros autores, para explicar y comprender el funcionamiento de las regiones metropolitanas actuales de los Estados Unidos y Europa occidental en relación directa con la perpetuación del modo de producción capitalista. El editor sintetiza las posturas de Brennery despliega algunas de las más relevantes 
causaciones dialécticas lefebvreanas entre el espacio, el Estado moderno, la urbanización capitalista y la reproducción del capital, aunque con matices a lo propuesto por el francés en su obra De l'État, Les contradictions de l'Étatmoderne (1978). ¿Cuáles son los "matices" de diferencia/ semejanza entre las concepciones de Estado presentes en Brenner y en Lefebvre? Sin posibilidad de entrar de lleno aquí en un desgranamiento pormenorizado de las ideas de cada uno, puede decirse de modo resumido que Lefebvre conceptualiza el Estado moderno como "un instrumento de la clase dominante", según una concepción ampliamente difundida para su época. Adversativamente, Brenner distingue y matiza entre un Estado del tipo keynesiano/social/fordista como agente activo de la regulación económica y las relaciones de dominación, frente a los de carácter poskeynesiano/neoliberal/posfordista partidarios del "libre mercado". Dicho esto, quedan configurados disímiles tipos de Estado capitalistas quede modo contrario a cualquier economicismo difieren en su respectivo "régimen de acumulación" y el "modo de regulación"; cada uno de ellos son producto y productores de espacialidades diferentes, tanto como de escalas geográficas anidadas a la circulación del capital y determinados objetos culturales. No obstante las diferencias señaladas entre Brenner y Lefebvre, las confluencias epistemológicas globales son profundas y refieren al modo en que la producción social del espacio capitalista es concebidopor ambos como una arquitectura social y política propia del Estado. De aquí se concluye en la convergencia que ambos autores podrían abrazar en cuanto a que el Estado es institucionalización política e institucionalización política del espacio.

El intercambio de ideas evidencia la influencia que ejercieron sobre Brenner algunos de los autores y conceptos más re- presentativos de los estudios urbanos contemporáneos, reconocibles desde los aportes de diferentes generaciones de "espacialistas" franceses y anglosajones; esto es, las ascendientes influencias metodológicas de los ya mencionados Lefebvre (1947) [1975] y David Harvey (2014) y los aportes del geógrafo irlandés Neil Smith. En estas páginas,el editor logra que el entrevistado analice,apretadamente aunque con profundidad,algunos de los aportes que los anteriores lograrandesde sus "conceptos claves"; por ejemplo y respectivamente: la "producción capitalista de espacio urbano" del filósofo y urbanista francés, el "desarrollo geográfico desigual" / "los arreglos espaciales del capitalismo" propios de Harvey, ylas "políticas de escala del capitalismo" según la perspectiva de Smith. Durante el transcurso de la conversación, entusiasmado por los interrogantes de Sevilla Buitrago, Brenner teje y desteje sus argumentos nada lineales en torno a la globalización y la neoliberalizacion actuales frente a la relación que ambos fenómenos mantienen con la urbanización contemporánea y sus modos de gobernanza.

La tercera sección está dedicada a una antología de textos del autor que posee un temario altamente diverso que va desde los estudios de políticas que tratan sobre el reescalamiento de la gobernanza urbana en la Unión Europea, hasta la propuesta de una nueva agenda y revisión de la teoría urbana para la investigación de la urbanización planetaria. En el recorrido que media entre uno y otro de los temas mencionados, se destacan artículos sobre: la globalización neoliberal y su acción de reterritorialización frente a determinados aspectos del keynesianismo espacial y la intervención activa del Estado; una suerte de propuesta de método que propone el estudio de las ciudades y las geografías del "neoliberalismo realmente existente"; la "glocalización" como una estrategia espacial estatal del empresarialismo 
urbano y la nueva política del desarrollo desigual europeo y el "desarrollo espacial desigual" como concepto derivado de la descripción fundacional de Marx sobre la circulación capitalista.

La cuarta sección está estructurada en torno a un sólo capítulo que corresponde a un texto inédito de Brenner y que asimila el período histórico y geográfico actual como el dela "era de la urbanización". Es un artículo que tiene entre sus objetivos proponer una clave epistemológica de lectura favorable a conceptualizar "la ciudad" y los procesos urbanos de manera radicalmente diferente. Allí, Brenner plantea -de modo teóricamente congruente con lo que desarrollamos hasta aquí- una superación de las formas establecidas de comprensión de lo urbano como un tipo de asentamiento delimitado o una condición nodal, hacia conceptualizaciones multiescalares, territorialmente diferenciadas, morfológicamente variadas y rigurosamente procesuales. Una vez más, el capítulo está sedimentado en diferentes obras de Lefebvre y ordenado a partir de sus in (certezas) referidas a la distinción urbano / no urbano y la adopción de la lógica "implosión / explosión" como factor explicativo de la urbanización planetaria.

La quinta sección del volumen corresponde a un breve "punto final" a cargo del editor estructurado en torno a seis ítems que pueden ser entendidos como un glosario finalde algunos conceptos centrales sobre los estudios urbanos críticos contemporáneos.El balance de la obra es altamente satisfactorio por varias razones,entre ellas porque permite conocer: a) algunos de los artículos que posicionaron a Brenner entre los principales referentes actuales del pensamiento urbano contemporáneo y sus puntos de vista sobre la ciudad, la urbanización y los procesos urbanos de la neoliberalizacion actualb) una serie de ensayos teóricos de carácter propedéutico, elaborados por el editor, que fueron adecuadamente intercalados a los fines de contextualizar, sintetizar y sistematizar numerosas ideas fuerza del autor, c) conexiones entre momentos y dimensiones diversas de la urbanización mundial atendiendo al "neoliberalismo realmente existente" y dependiente de marcos regulatorios, instituciones, actores sociales y geografías urbanas que se proponen metodológicamente y respectivamente singulares d) análisis urbanos integradores de momentos y dimensiones de la urbanización (económicas, políticas, culturales y ambientales) que contribuyen significativamente a enriquecer los planteos abstractos lefebvreanos, principalmente aquellos que ponen en evidencia las conexiones entre las practicas espaciales, las regulaciones territoriales y la vida cotidiana. Para terminar, es probable que para nuestros países del Sur las metrópolis estudiadas por Brenner resulten "lejanas" y significativamente diferentes a las que habitamos en la "periferia capitalista"; sin embargo, la expresión referida a la neoliberalización "realmente existente" es una invitación obligada (mediante el estudio del contexto socio-político y las trayectorias institucionales previas) a dejar de lado cualquier generalización abstracta y transposición mecánica de realidades urbanas bien diferentes, como son las metrópolis situadas al Norte y al Sur del planeta e incluso aquellas que pudieran compararse entre las metrópolis de cada uno de estos hemisferios.

Mg. Gabriel Horacio Álvarez Universidad Nacional Tres de Febrero/ Universidad Nacional General San Martín/ Universidad Nacional del Centro de la Provincia de Buenos Aires 


\section{Referencias bibliográficas}

LEFEBVRE, H. (1947). Logique formelle, logique dialectique, Paris: Éditions Sociales $\left(3^{\mathrm{a}}\right.$ ed., Paris: Messidor-Éditions, 1982) [traducción castellano: (1975) Lógica formal, lógica dialéctica, Madrid: Siglo XXI].

LEFEBVRE, H. (1978). De l'État, Paris: UGE (Selección de fragmentos en: https://marxismocritico.com/2017/09/08/el-espacio-y-elestado/. Consultado el 20 de febrero de 2014.

HARVEY, D. (2014). Diecisiete contradicciones $y$ el fin del capitalismo. Madrid: Traficantes de sueños. 